\title{
Study of Intercultural Adaptation of Foreign Students in Agricultural Universities
}

\author{
Xin Cheng, Yang Lin \\ Jilin Agricultural University, 130118, Changchun, Jilin Province, China
}

Keywords: Agricultural Universities, Foreign Students, Intercultural Adaptation

\begin{abstract}
Agricultural Universities have made certain achievements and progress in education for overseas students, especially, the annual growth rate of the number of foreign students is relatively fast. It occurred numerous intercultural adaptation issue during foreign students' studying and living, these issues not only directly cause students' learning effect and academic success or failure, but also go against the establishment of friendly images of universities and even the state. According to my personal practical experience in teaching Chinese for foreign students and the management of foreign students, and conducted surveys for foreign students at school, taking Jilin Agricultural University as an example to analyze the issues and solutions for intercultural study, communication and life of foreign students.
\end{abstract}

\section{Introduction}

In 2016, National Foreign Students Working Conference has clearly put forward that working on foreign students education is supposed to be based on the policy "Double World-Classes", overall diplomacy strategy, insisting on the policy of management regulation and connotation development, to cultivate large number of international talents who knows China well with amity. Agricultural Colleges and Universities are the important part of the higher education system. It has the special trait for developing foreign students education in China, for instance, the profound history, distinctive majors, solid foundation of education and so on. Promoting internationalization for agricultural colleges and universities requires active development of foreign students education, also to enhance the level of our higher education and international reputation. Due to the characters of agricultural colleges and universities, it occurred numerous issues about intercultural adaptation for foreign students' studying and living in China. These issues not only directly cause students' learning effect and academic success or failure, but also go against the establishment of friendly images of universities and even the state. According to my personal practical experience in teaching Chinese for foreign students and the management of foreign students, and conducted surveys for foreign students at school, taking Jilin Agricultural University as an example to analyze the issues and solutions for intercultural study, communication and life of foreign students.

\section{Current Development of Foreign Students' Education in Agricultural Universities}

The number of foreign students in agricultural universities has increased from 827 in 2006 to 5740 in 2015, the number has increased by seven times, annually 24\% in average, higher than that whole state foreign students growth rate,11\%. However, seen by the number of agricultural universities, in 2006, there were 16 universities which admitted foreign students, $0.51 \%$ of the proportion in state. In 2015, there were 31 universities which admitted foreign students, but 1.44\% of proportion in state [Data from brief statistics of foreign students in China 2006- 2015 by Ministry of education international cooperation and Exchange Division]As a whole, The total number of foreign students grew slowly with low proportion in state for the last decade. The reality of small scale of foreign students in agricultural universities does not match the important position in higher education system.

The distribution of foreign students in agricultural universities is imbalanced. For instance, in 
2015, among the top five number of foreign students [Nanjing Agricultural University, Zhejiang A\&F University, Northwest A\&F University, Huazhong Agricultural University, China Agricultural University], four of them are directly under the Ministry of Education. These five agricultural universities has taken up half number of foreign students in agricultural ones. With the advantages of their own disciplines and the strength of running schools, the subordinate agricultural colleges and universities have become the first choice for foreign students to study in China. Otherwise, Provincial Agricultural Colleges and universities rely on their own regional advantages and characteristics, are becoming the emerging powers to develop foreign students education. Jilin Agricultural University, represents the provincial agricultural universities, has expanded the scale of foreign students. The study of its development and the cultural adaptability of foreign students are of great significance for the overall study of Agricultural Universities based on fast growth. The foreign students in Jilin Agricultural University mostly belong to CSC students, small number of self-supported students, most of students from the countries like Africa and Asia which are along the policy "The Belt, The Road", African students take up $40 \%$ of all , great number of countries with small number of foreign students.

\section{The Issues of Intercultural Adaptation for Foreign Students in Agricultural Universities}

Due to the sporadic countries in Jilin Agricultural University, students open the distance because of personal cultural differences. As far as I am concerned, with my practical experience in teaching and managing foreign students, to pin point the following issues from culture, study and life.

\subsection{Physical and Mental Adjustment Difficulties Caused by Changes in Living Conditions}

Jilin Agricultural University is located in the city of Changchun which has a long term winter. Foreign students need to face the gradual cooling of the climate after September every year. It is a great challenge for the students who are from Africa and South Asia to face a long cold and dry winter. The climate like this can easily cause foreign students feel not well, and this leads to the difficult learning, hypothesized. During the period of studying, it has occurred casually that students missed the lessons because of illness. These negative factors not only effected the academic accomplishment, but also for adapting Chinese culture. With the increasing number of foreign students these years, we have observed the multiple issues that happened to the students, some of the issues caused by inadaptation of climate, such as different eating habit, changing the living environment, inconvenient transportation, those can increase the difficulties to adapt life for foreign students.

\subsection{Cultural Background Difference Arouses Unfavorable Social Communication}

There are three aspects foreign students' interpersonal communication, first is to communicate with people from many other countries, it is a major feature which is numerous countries, so far, there are more than 100 students from 22 countries. The difference of religion and eating custom lead to the main communication barriers. Second is communicating with Chinese students or teachers, most of the students wish to establish good social relationship with Chinese people, yet, foreign students' communicating with Chinese people is still on the surface in the way of chatting because of personality, cultural difference, and not able to achieve further associate. For Chinese students, most of them are not open mind, shy characteristics, when facing foreign students, they usually flinch to communicate. The foreign students with Asian cultural environment require similar personality with Chinese students, they would rather communicate with native friends, so it is hard for them to blend in other countries. The third is that students from the same country will found an united association for themselves, if study in the same city, they prefer to join such association more than others. However, the time for their interaction is limited by far distance between universities and academic pressure.

\subsection{Language Barriers Lead to Communication Barriers}

The foreign students in Jilin Agricultural university are the starters for learning Chinese language. 
After studying one or half year Chinese, due to personal language learning ability and studying attitude etc, the level of Chinese learning has a relatively far disparity. Utilizing Chinese as a interlanguage to communicate with other foreign students is not common, therefore, it causes the difficulties in communicating with their teachers and Chinese students and understanding each other. English as an official language in most of African countries, is many African students' native tongue, it is easy to communicate with each other as well, whereas, as for Asian countries, especially students from Russia, Mongolia and etc, the English level is lower, language barriers lead to main problem communicating with other country students.it is a common scene that students from same country communicate with each other, therefore, it illustrates language is the major factor to establish a social communication.

\section{Strategy for Improving Intercultural Adaptation of Foreign Students}

\subsection{Provide a friendly living environment by strengthening the construction of campus hardware facilities}

Provide students dormitories and canteens which are only for foreign students, different needs of foreign students' dormitory require to be taken into full consideration. Room designing should differ from Chinese students' dormitory. Coffee bar and Canteen are supposed to be set up in the dormitory, introducing international western food franchised outlet is considerable. Complete the gymnasium facilities under existing campus facilities and open to all foreign students. All in all, it is one of the crucial requirements that internationalize the campus hardware facilities.

\subsection{Improving foreign students management teamwork and internationalize teaching level}

It is considerable to improve the internationalization of Jilin Agriculture University, in general, Students and teachers in Jilin Agricultural University are short of experience studying abroad and communicating with foreigners, less understand other country culture and weak in awareness of intercultural communication. It directly affects the communication with foreign students and Chinese teachers, students. therefore, improving teachers' internationalization level is very crucial.

Improve the foreign students administrator's intercultural awareness. There are plenty of conflicts during daily management working, as a foreign student administrator, when facing the students from all over the world with different politic background, cultural background, religion have the difficulties in adapting psychology and body, I am supposed to communicate with them often, help them solve the practical problem. Foreign students administrators require to be cultivated to own internationalized mind, to interact with foreign students in the face of state and national cultural difference.

As Chinese language teachers and professional subject teachers. They are the important promoters for foreign students studying in China. Their cultural concept and ideology will deeply influence foreign students. Therefore, it is crucial to improve teacher's internationalization, provide the opportunity studying abroad for teachers whose job is relative with foreign students management. Only do teachers establish a wide range of other countries cultural awareness and psychological identity, in order to objectively treat students of different cultural backgrounds can make a good effort in teaching work.

\subsection{Degree of Participation in Campus Culture}

After foreign students entering university, Chinese students should be considered to associate foreign students' settlement. Organize the visiting activity to introduce campus and city. For the room distribution, different religions, eating habits, lifestyles are supposed to be considered to avoid conflicts.

Encourage foreign students to join the Chinese students associations and association for foreign students. Campus is the main place of residence, also the place to adapt Chinese culture. Varieties of activities organized by associations not only attract Chinese students, but also for foreign students. foreign students should join the association based on own hobby. It is also a way to blend 
in Chinese culture. Foreign students management office is supposed to encourage and support the students association for foreign students, to enable students to enjoy cultural adaptation and cultural integration in a collective environment.

In a word, the intercultural adaptation of foreign students during their study in China should arouse the attention of foreign students management teachers. Agricultural Higher Education in China is facing an increasingly accelerated internationalization process, it is urgent to upgrade the school hardware facilities and improve the humanism constitution.

\section{Acknowledgements}

Fund Project: Ministry of Education in Jilin Province The 13th Five-year Social science research project 2017: Cultural conflicts and integration between Chinese and foreign students in the context of internationalization of Education -- a case study of universities in Jilin (Project number: JJKH20170325SK.

Ministry of Education in Jilin Province The 13th Five-year Social science research project 2017: Present situation and Countermeasures of scholarship program for foreign students in Jilin(JJKH20170331SK) periodicity research findings.

Ministry of Education in Jilin Province The 13th Five-year Social science research project 2016: The construction of cultivating platform for postgraduate practice skills in agricultural colleges and universities (Project number: UNESCO 2016) no. 143)

(Author department: Jilin Agricultural University)

About the Author:

Cheng Xin (1983-), female, born in Guan county, Shandong province, master degree, lecturer.

Research direction: international Chinese language education, Teaching of Chinese as a Foreign Language.

Post address: Xin Cheng Street, 2888, Jilin Agricultural University, International Exchange and Corporation Office.

Phone:18604429826

Email: chengxin@jlau.edu.cn

Lin Yang (1984.8-) female, Han, born in Jilin City, lecturer,

Research Direction: Teaching of Chinese as a Foreign Language.

Jilin Agricultural University, International Education College.

\section{References}

[1] Qiang Baifa, Current situation, problems and Countermeasures of foreign students' education development in Agricultural Universities of China] [J]. Yunnan Agricultural University Journal, 2014(7)

[2] Ma Xiangyang, Wei La, Intercultural adaptation of foreign students under the perspective of sensitivity theory[J]. Shenyang Agricultural University Journal 2014(7). 